\title{
Desempenho Produtivo de Animais de Quatro Raças Zebuínas, Abatidos em Três Estádios de Maturidade. 2. Características da Carcaça ${ }^{1}$
}

\author{
André Mendes Jorge ${ }^{2}$, Carlos Augusto de Alencar Fontes ${ }^{3}$, Mário Fonseca Paulino ${ }^{4}$, Paulo \\ Gomes Júnior ${ }^{5}$, Juliana Nardelli Ferreira ${ }^{5}$
}

\begin{abstract}
RESUMO - Com a finalidade de estudar as características da carcaça, nove animais Gir, nove Guzerá, nove Nelore e nove Mocho-Tabapuã não-castrados, com idade média de 24 meses e pesos vivos médios iniciais de 357,6; 362,0; 368,6; e 376,4 kg, respectivamente, foram usados neste estudo. Em cada raça, os animais foram distribuídos aleatoriamente em baias individuais, recebendo ração contendo $50 \%$ de concentrado na matéria seca à vontade e divididos em três pesos de abate (categorias 405, $450 \mathrm{e} 500 \mathrm{~kg} \mathrm{PV}$ ). No abate, determinou-se o peso de corpo vazio. Não houve diferenças entre raças ou pesos de abate para as variáveis estudadas, exceto para rendimento de alcatra completa. Para esta característica, houve efeito de interação entre raça e categoria, sendo que o rendimento decresceu em animais Gir com a elevação do peso de abate, o que não ocorreu nas demais raças. Não houve diferenças entre as raças com relação à composição física. O peso de abate não influenciou a composição física da carcaça e a área de olho de lombo, mas influiu no comprimento de carcaça e na espessura de gordura.
\end{abstract}

Palavras-chave: área de olho de lombo, bovino de corte, características de carcaça, composição física, comprimento, espessura de gordura, zebuínos

\section{Productive Performance of Four Zebu Breed Beef Cattle Slaughtered at Different Stages of Maturity. 2. Carcass Traits}

\begin{abstract}
With the aim to study carcass traits, nine Gyr, nine Guzera, nine Nellore and nine Mocho Tabapuã bulls, averaging, respectively, 357.6, 362.0, 368.6, and $376.4 \mathrm{~kg}$ of initial live weight and 24 months of age were used in this study. The animals from each breed were randomly assigned to individual pens and were full fed a diet containing $50 \%$ concentrate, dry matter basis, until the slaughter weights $(405,450$ and $500 \mathrm{~kg} \mathrm{LW})$. At slaughter the empty body weight was determined. There were no differences among breeds or slaughter weights on the traits studied, except for whole "alcatra" cut yield. For this trait there was a interaction effect between breed and category. The yield decreased in Gyr breed, as slaughter weight increased, but did not change in the other breeds. There were no differences among breeds regarding to any one of the physical composition. Slaughter weight did not influence carcass physical composition and loin eye area, however affected the carcass length and back fat thickness.
\end{abstract}

Key Words: loin eye area, beef cattle, carcass traits, physical composition, length, back fat thickness, zebu

\section{Introdução}

Apesar de as pesquisas sobre as características das carcaças de bovinos, no Brasil, terem crescido substancialmente, os resultados sobre composição física (rendimento de carcaça e de seus cortes primários, proporções de tecidos e suas relações, entre outros) e composição química, às vezes, têmse mostrado contraditórios, principalmente quando se comparam raças zebuínas.

Por ocasião do abate, a estimativa das características da carcaça é de suma importância para comple- mentar a avaliação do desempenho do animal durante o seu desenvolvimento.

O objetivo do presente estudo foi avaliar o desempenho, em confinamento, de bovinos das raças Gir, Guzerá, Nelore e Mocho Tabapuã, abatidos em diferentes estádios de maturidade.

\section{Material e Métodos}

O presente estudo foi realizado no Departamento de Zootecnia da Universidade Federal de Viçosa.

Foram utilizados dados de 36 bovinos machos não-

\footnotetext{
${ }^{1}$ Parte da Tese apresentada à UFV pelo primeiro autor, para obtenção do título de Doctor Scientiae. Trabalho realizado em colaboração com a EPAMIG/FAPEMIG.

2 Professor Assistente Doutor do D.P.E.A./ UNESP - Faz. Lageado, Caixa Postal 560 - Botucatu - SP. 18618-000. E-mail: jorgeam@fca.unesp.br ${ }^{3}$ Professor Titular UENF - 28015-620 - Campos, RJ.

${ }^{4}$ Professor do Departamento de Zootecnia da UFV, Viçosa - MG.

${ }^{5}$ Bolsista Iniciação Científica UFV.
} 
castrados, sendo nove Gir (GIR), nove Guzerá (GUZ), nove Nelore (NEL) e nove Mocho Tabapuã (TAB), com idade média de 24 meses e pesos médios iniciais de $357,6 \pm 32,95 ; 362,0 \pm 28,95 ; 376,4 \pm 28,56 ;$ e $368,6 \pm$ $25,83 \mathrm{~kg}$, respectivamente, provenientes da Fazenda Experimental da EPAMIG, Governador Valadares, Minas Gerais. Estes animais foram confinados em baias individuais concretadas com área de $30 \mathrm{~m}^{2}$, oito das quais eram cobertas com telhas de cimento amianto, dispondo de comedouro e bebedouro de cimento.

Os animais de cada raça foram distribuídos aleatoriamente em três grupos de alimentação à vontade e receberam ração formulada segundo as normas do NRC (1984), de modo a permitir ganho médio diário de peso vivo de $1,1 \mathrm{~kg}$, contendo, na matéria seca, $50 \%$ de feno de capim braquiária e 50\% de concentrado, até atingirem pesos vivos (PV) de abate de 405,450 e $500 \mathrm{~kg}$, equivalentes a 90, 100 e $110 \%$ do peso vivo à maturidade das fêmeas das raças correspondentes (categorias 405, 450 e $500 \mathrm{~kg} \mathrm{PV}$, respectivamente). O concentrado constituiu-se de $76,5 \%$ de milho em grão triturado, $20,1 \%$ de farelo de soja, $1,6 \%$ de uréia e 1,8 de mistura mineral. A composição química da ração é apresentada na Tabela 1 .

O período experimental não teve duração préfixada, uma vez que os animais foram abatidos assim que atingiram os pesos pré-estabelecidos de 405,450 ou $500 \mathrm{~kg}$. Os animais foram pesados a cada 28 dias e, à medida que um animal se aproximava do peso de abate preestabelecido, era pesado a intervalos menores, de forma a ser abatido com o peso previsto.

Ao atingir o peso de abate, o animal foi submetido a período de 16 horas de jejum de sólidos.

A carcaça era dividida em duas metades, com o auxílio de serra elétrica, e estas pesadas individualmente. O comprimento da meia-carcaça direita foi medido com fita métrica de alumínio, partindo-se da porção anterior medial da primeira costela até o ponto médio da curvatura do osso púbis. Em seguida, as duas metades da carcaça foram levadas à câmara fria, onde permaneceram por aproximadamente 18 horas, à temperatura de $-5^{\circ} \mathrm{C}$. Decorrido este tempo, utilizando-se a metade esquerda da carcaça, determinou-se a composição física da carcaça, retirandose a seção transversal, incluindo as $9^{\mathrm{a}}, 10^{\mathrm{a}}$ e $11^{\mathrm{a}}$ costelas, da qual se destacou a seção $\mathrm{HH}$, segundo o protocolo de HANKINS e HOWE (1946).

$\mathrm{Na}$ meia-carcaça esquerda, à altura da $12^{\mathrm{a}}$ costela, foram medidas a área de olho do músculo Longissimus dorsi (área de olho de lombo - AOL) e espessura de gordura subcutânea.
Tabela 1 - Composição química da ração experimental (\% MS)

Table 1 - Chemical composition of the experimental diet (\% DM)

Matéria seca (Dry matter) 83,78

Proteína bruta (Crude protein) 12,71

Energia metabolizável (Metabolizable energy) ${ }^{1} \quad 2,42$

$\mathrm{Ca} \quad 0,42$

$\mathrm{P} \quad 0,22$

$\mathrm{Mg} \quad 0,09$

K $\quad 0,81$

$\begin{array}{lr}\mathrm{Na} & 0,06\end{array}$

${ }^{1}$ Determinado em ensaio de digestibilidade; EM =ED x0,82(PAULINO, 1996)(Mcalkg).

${ }^{1}$ Determined from digestibility trial; ME =DEx 0.82 (PAULINO, 1996) (Mcalkg).

Na meia-carcaça direita, foi determinado o rendimento dos cortes primários: paleta, acém, ponta de agulha, alcatra completos e coxão.

A estimativa do peso corporal vazio (PCVZ) inicial dos animais experimentais (categorias 405, 450 e $500 \mathrm{~kg} \mathrm{PV}$ ) foi feita por meio do abate de um lote extra, oriundo do mesmo rebanho da EPAMIG, ou seja, de três animais de cada raça (animais-referência), semelhantes quanto ao peso e à condição corporal dos animais experimentais, somando-se os pesos de carcaça, sangue, cabeça, pés, couro, cauda e vísceras. Relações específicas entre o peso corporal vazio e o vivo dos animais-referência foram determinadas para cada raça e utilizadas para se estimar o peso corporal vazio inicial dos animais experimentais (categorias 405, 450 e $500 \mathrm{~kg} \mathrm{PV).} \mathrm{O} \mathrm{peso} \mathrm{corporal}$ vazio final destes animais foi determinado de modo semelhante aos animais-referência.

As análises estatísticas foram feitas utilizando-se o programa LSMLMW, versão PC-1, segundo HARVEY (1987), utilizando-se o modelo abaixo:

em que

$$
\mathrm{Y}_{\mathrm{ijk}}=\mu+\mathrm{R}_{\mathrm{i}}+\mathrm{C}_{\mathrm{j}}+\mathrm{RC}_{\mathrm{ij}}+\mathrm{e}_{\mathrm{ijk}}
$$

$\mathrm{Y}_{\mathrm{ijk}}=$ observação referente ao animal k, da raça i e categoria $\mathrm{j}$;

$\mu=$ média geral;

$\mathrm{R}_{\mathrm{i}}=$ efeito da raça $\mathrm{i}$, em que $\mathrm{i}=1$, (GIR); 2, (GUZ); 3,(NEL); 4, (TAB);

$\mathrm{C}_{\mathrm{j}}=$ efeito da categoria $\mathrm{j}$, em que $\mathrm{j}=1,(405 \mathrm{~kg})$; $2(450 \mathrm{~kg})$ e $3(500 \mathrm{~kg} \mathrm{PV})$;

$\mathrm{RC}_{\mathrm{ij}}=$ efeito da interação entre raça i e categoria $\mathrm{j}$; e $\mathrm{e}_{\mathrm{ijk}}=$ erro aleatório, pressuposto $\operatorname{NID}\left(0, \sigma^{2}\right)$.

$\mathrm{O}$ efeito de regressão, por raça e geral, do PCVZ inicial para as características estudadas foi pesquisado anteriormente em análises preliminares, sendo excluído do modelo, por não se mostrar significativo.

As médias foram comparadas pelo teste Tukey a $5 \%$ de probabilidade. 


\section{Resultados e Discussão}

As análises de variância para rendimento de carcaça e dos cortes dianteiro, paleta e acém completos, traseiro total, traseiro especial, coxão e ponta-deagulha, para comprimento de carcaça (COMPCAR), espessura de gordura subcutânea (ESPGOR) e área de olho de lombo (AOL) e para as proporções de músculos, tecido adiposo e ossos, e também para as relações entre os mesmos, na carcaça, mostraram não haver efeito significativo de interação entre raças (Gir, Guzerá, Nelore e Mocho Tabapuã) e categorias (405 kg, $450 \mathrm{~kg}$ e $500 \mathrm{~kg} \mathrm{PV}$ ), sendo, portanto, os dois efeitos considerados independentemente.

A Tabela 2 apresenta os rendimentos de carcaça e de seus cortes básicos dos animais das diferentes raças e categorias. Os valores de rendimento de carcaça em relação ao peso vivo (RPV) apresentados pelos zebuínos do presente estudo guardam perfeita concordância com os dados disponíveis na lite- ratura, que mostram rendimentos de carcaça em torno de 54\%, o que é considerado bom (GONÇALVES, 1988; GALVÃO et al., 1991; PERON et al., 1993; MOLETTA e RESTLE, 1996, ESTRADA, 1996; e JORGE et al., 1997b).

Não houve diferença entre raças em relação à porcentagem dos cortes dianteiro, paleta e acém completos, traseiro total, traseiro especial e ponta de agulha. Estes resultados guardam estreita concordância com os encontrados por MOLETTA e RESTLE (1996) e JORGE et al. (1997b) e poderiam ser atribuídos à taxa de crescimento semelhante das diferentes partes do corpo (órgãos e vísceras), nas diferentes raças.

O peso de abate não teve, igualmente, influência significativa sobre os rendimentos de carcaça (RPCVZ), dianteiro, paleta completa, traseiro total e coxão. Os aumentos nos valores numéricos observados com a elevação da maturidade dos animais estão de acordo com BERG e BUTTERFIELD (1976), que afirmam que o rendimento de carcaça se eleva com

Tabela 2 - Médias dos rendimentos de carcaça e de seus cortes básicos, por raça e por categoria ${ }^{1}$ Table 2 - Means of carcass dressing, and their basic cuts by breed and by category

\begin{tabular}{|c|c|c|c|c|}
\hline \multirow[t]{3}{*}{ Item } & \multicolumn{4}{|c|}{$\begin{array}{l}\text { Raça } \\
\text { Breed }\end{array}$} \\
\hline & Gir & Guzerá & Nelore & Mocho Tabapuã \\
\hline & Gyr & Guzera & Nellore & \\
\hline & \multicolumn{4}{|c|}{ 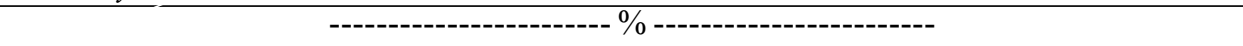 } \\
\hline $\mathrm{RPV}(C D L W)$ & $53,90 \pm 0,56 a$ & $54,39 \pm 0,56 \mathrm{a}$ & $54,32 \pm 0,56 \mathrm{a}$ & $53,64 \pm 0,56 a$ \\
\hline $\operatorname{RPCVZ}(C D E B W)$ & $62,60 \pm 0,48 \mathrm{a}$ & $62,22 \pm 0,48 \mathrm{a}$ & $63,25 \pm 0,48 \mathrm{a}$ & $62,16 \pm 0,48 \mathrm{a}$ \\
\hline Dianteiro $(H Q Y)$ & $41,99 \pm 0,87 \mathrm{a}$ & $42,84 \pm 0,87 \mathrm{a}$ & $40,76 \pm 0,87 \mathrm{a}$ & $41,20 \pm 0,87 a$ \\
\hline Paleta completa (WSY) & $18,37 \pm 0,58 \mathrm{a}$ & $19,36 \pm 0,58 \mathrm{a}$ & $18,78 \pm 0,58 \mathrm{a}$ & $18,70 \pm 0,59 a$ \\
\hline Acém completo $(W A C Y)$ & $23,62 \pm 0,54 \mathrm{a}$ & $23,48 \pm 0,54 \mathrm{a}$ & $21,97 \pm 0,54 \mathrm{a}$ & $22,50 \pm 0,55 \mathrm{a}$ \\
\hline Traseiro total $(F Q Y)$ & $58,01 \pm 0,87 \mathrm{a}$ & $57,16 \pm 0,87 \mathrm{a}$ & $59,24 \pm 0,87 \mathrm{a}$ & $58,80 \pm 0,88 \mathrm{a}$ \\
\hline Traseiro especial (PSCY) & $46,00 \pm 0,74 \mathrm{a}$ & $45,40 \pm 0,74 \mathrm{a}$ & $47,73 \pm 0,74 \mathrm{a}$ & $46,92 \pm 0,75 \mathrm{a}$ \\
\hline Coxão $(R Y)$ & $25,88 \pm 0,69 a$ & $26,04 \pm 0,69 a$ & $27,86 \pm 0,69 a$ & $27,05 \pm 0,70 \mathrm{a}$ \\
\hline Ponta de agulha (SRY) & $12,01 \pm 0,31 \mathrm{a}$ & $11,76 \pm 0,31 \mathrm{a}$ & $11,51 \pm 0,31 \mathrm{a}$ & $11,87 \pm 0,32 \mathrm{a}$ \\
\hline \multirow[t]{3}{*}{ Item } & \multicolumn{4}{|c|}{ Categoria } \\
\hline & \multicolumn{4}{|c|}{ Category } \\
\hline & $405 \mathrm{~kg}$ PV $(L W)$ & $450 \mathrm{~kg} P V(L W)$ & \multicolumn{2}{|c|}{$500 \mathrm{~kg} P V(L W)$} \\
\hline & & 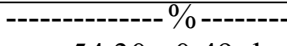 & \multirow{2}{*}{\multicolumn{2}{|c|}{$55,19 \pm 0,48 \mathrm{a}$}} \\
\hline $\mathrm{RPV}(C D L W)$ & $52,74 \pm 0,48^{b}$ & $54,30 \pm 0,49 \mathrm{ab}$ & & \\
\hline $\operatorname{RPCVZ}(C D E B W)$ & $61,85 \pm 0,41^{\mathrm{a}}$ & $62,64 \pm 0,42 \mathrm{a}$ & \multicolumn{2}{|c|}{$63,17 \pm 0,41 \mathrm{a}$} \\
\hline Dianteiro $(H Q Y)$ & $41,14 \pm 0,75^{\mathrm{a}}$ & $41,33 \pm 0,76 a$ & \multicolumn{2}{|c|}{$42,63 \pm 0,75 a$} \\
\hline Paleta completa (WSY) & $19,00 \pm 0,51^{\mathrm{a}}$ & $18,86 \pm 0,51 \mathrm{a}$ & \multicolumn{2}{|c|}{$18,56 \pm 0,51 \mathrm{a}$} \\
\hline Acém completo $(W A C Y)$ & $22,13 \pm 0,47 b$ & $22,47 \pm 0,48 b$ & \multicolumn{2}{|c|}{$24,07 \pm 0,47 \mathrm{a}$} \\
\hline Traseiro total $(F Q Y)$ & $58,16 \pm 0,75 \mathrm{a}$ & $58,67 \pm 0,76 \mathrm{a}$ & \multicolumn{2}{|c|}{$57,37 \pm 0,75 \mathrm{a}$} \\
\hline Traseiro especial (PSCY) & $47,67 \pm 0,64 \mathrm{a}$ & $46,89 \pm 0,65 \mathrm{ab}$ & \multicolumn{2}{|c|}{$44,97 \pm 0,64 b$} \\
\hline Coxão $(R Y)$ & $27,47 \pm 0,60 \mathrm{a}$ & $26,92 \pm 0,61 \mathrm{a}$ & \multicolumn{2}{|c|}{$25,73 \pm 0,60 a$} \\
\hline Ponta de agulha (SRY) & $11,20 \pm 0,27 b$ & $11,78 \pm 0,27 \mathrm{ab}$ & \multicolumn{2}{|c|}{$12,40 \pm 0,27 \mathrm{a}$} \\
\hline
\end{tabular}

${ }_{1}^{1}$ Médias, na linha, seguidas por letras diferentes são diferentes $(P<0,05)$ pelo teste Tukey.

${ }^{2} \mathrm{RPV}=$ Rendimento de carcaça em relação ao peso vivo; RPCVZ = Rendimento de carcaça em relação ao peso corporal vazio. $\mathrm{PV}=$ peso vivo.

${ }^{1}$ Means, within a row, followed by different letters are different $(P<.05)$ by Tukey test.

${ }^{2} C D L W=$ Carcass dressing in relation to live weight; $C D E B W=$ Carcass dressing in relation to empty body weight; $H Q Y=$ Hindquarter yield; $W S Y=W h o l e ~ s h o u l d e r$ yield; $W A C Y=$ Whole acem yield; $F Q Y=$ Forequarter yield; $P S C Y=$ pistola style cut yield; $R Y=$ Round yield; $S R Y=$ Spare ribs yield; $L W=$ live weight. 
o aumento do peso do animal.

As indicações de rendimento ligeiramente superior de dianteiro e menor de traseiro em animais abatidos com 500 kg PV não atingiram a significância, mostrando que o dimorfismo sexual típico de machos não-castrados, que acarreta maior desenvolvimento do dianteiro em animais adultos, não havia ainda se manifestado, de forma acentuada, nos animais das quatro raças zebuínas, apesar destes animais terem apresentado maior $(\mathrm{P}<0,05)$ rendimento de acém. Estes resultados são semelhantes aos encontrados por ESTRADA (1996) e JORGE et al. (1997b), que abateram bovinos Nelore com pesos semelhantes aos adotados no presente trabalho.

$\mathrm{O}$ rendimento de traseiro especial foi maior $(\mathrm{P}<0,05)$ em animais abatidos aos $405 \mathrm{~kg} \mathrm{PV}$ e menor $(\mathrm{P}<0,05)$ nos de $500 \mathrm{~kg} \mathrm{PV}$, enquanto os animais abatidos aos $450 \mathrm{~kg}$ PV não diferiram dos demais. Observou-se comportamento oposto para rendimento de ponta de agulha, que foi maior $(\mathrm{P}<0,05) \mathrm{em}$ animais aos $500 \mathrm{~kg}$ PV em comparação aos de $405 \mathrm{~kg}$ $\mathrm{PV}$, não tendo as duas categorias diferido da categoria abatida aos $450 \mathrm{~kg}$ PV. As diferenças supracitadas podem ter ocorrido ao se secionar a ponta de agulha, deixando-se, involuntariamente, porções de costelas proporcionalmente maiores em animais mais pesados, pois, quando se comparou o rendimento de traseiro total (soma da ponta de agulha + traseiro especial), não ocorreu diferença entre os pesos de abate. Deve-se ressaltar que o local em que se faz o destaque da ponta de agulha é determinado, até certo ponto, de forma subjetiva.

A análise de variância para rendimento de alcatra completa mostrou existir efeito de interação $(\mathrm{P}<0,01)$ entre raça e categoria. Na Tabela 3 verifica-se decréscimo $(\mathrm{P}<0,05)$ no rendimento de alcatra completa em animais Gir com a elevação do peso de abate e menor rendimento em animais Nelore da categoria $500 \mathrm{~kg}$ PV em relação à categoria $405 \mathrm{~kg}$ PV, não ocorrendo diferenças entre categorias, nas demais raças. Comparando o rendimento desse corte entre raças, dentro de cada categoria (peso) de abate, observou-se que, na categoria $405 \mathrm{~kg} \mathrm{PV}$, o Gir apresentou maior valor $(\mathrm{P}<0,05)$; o Guzerá e o Mocho Tabapuã, menor $(\mathrm{P}<0,05)$; e o Nelore, valor intermediário $(\mathrm{P}<0,05)$ de rendimento. Na categoria $450 \mathrm{~kg}$ $\mathrm{PV}, \mathrm{NEL}$ e TAB apresentaram maior valor $(\mathrm{P}<0,05)$; GUZ, menor $(\mathrm{P}<0,05)$ e o GIR não diferiu deste e dos primeiros. Na categoria $500 \mathrm{~kg} \mathrm{PV}, \mathrm{TAB}$ apresentou maior valor $(\mathrm{P}<0,05)$; GIR e NEL, menor $(\mathrm{P}<0,05) \mathrm{e}$ GUZ não diferiu destes e do primeiro. Fisiologicamente não se encontra explicação para o comportamento diferente das raças.

$\mathrm{Na}$ Tabela 4 são apresentados os valores de comprimento de carcaça (COMPCAR), espessura de gordura subcutânea (ESPGOR) e área de olho de lombo (AOL), expressos em termos absolutos ou em \% PCVZ, para os animais das quatro raças e das três categorias de abate (405, 450 e $500 \mathrm{~kg}$ PV). Não houve diferença entre raças, quanto aos valores de COMPCAR, ESPGOR e AOL, expressos em valores absolutos e em \% PCVZ. O valor de COMPCAR, em \% PCVZ, para animais Nelore, do presente estudo, situa-se entre os valores de 0,33 e 0,39 encontrados por GALVÃO et al. (1991) e JORGE et al. (1997a), respectivamente. O comprimento de carcaça, expresso em \% PCVZ, ou quando o abate ocorre a peso constante dá idéia de compacidade do animal.

A ESPGOR dos animais das quatro raças (entre 2,77 e 3,44 mm) foi inferior aos valores de 5,03 e 4,33 mm encontrados por GAZZETTA et al. (1995) e MOLETTA e RESTLE (1996) e superior aos valores de 2,36 e 2,54 mm encontrados por PERON et al., (1995) e JORGE et al. (1997a), respectivamente. Ressaltase que a gordura, além de influir no aspecto visual da carcaça, na porção comestível e na qualidade da carne, serve também como proteção contra desidratação no resfriamento da carcaça. Admite-se que espessura de

Tabela 3 - Média do rendimento de alcatra completa por raça e categoria ${ }^{1}$

Table 3 - Mean of the whole rump yield per breed and category

\begin{tabular}{|c|c|c|c|c|}
\hline $\begin{array}{l}\text { Categoria } \\
\text { Category }\end{array}$ & & $\begin{array}{l}\text { Raça } \\
\text { Breed }\end{array}$ & & \\
\hline & Gir & Guzerá & Nelore & Mocho Tabapuã \\
\hline & Gyr & Guzera & Nellore & \\
\hline $405 \mathrm{~kg}$ PV $(L W)$ & $21,95 \pm 0,37 \mathrm{Aa}$ & $19,28 \pm 0,37 \mathrm{Ac}$ & $20,30 \pm 0,37 \mathrm{Ab}$ & $19,27 \pm 0,37 \mathrm{Ac}$ \\
\hline $450 \mathrm{~kg} \mathrm{PV}(L W)$ & $19,97 \pm 0,37 \mathrm{Bab}$ & $19,31 \pm 0,37 \mathrm{Ab}$ & $20,24 \pm 0,37 \mathrm{Aa}$ & $20,36 \pm 0,39 \mathrm{Aa}$ \\
\hline $500 \mathrm{~kg}$ PV $(L W)$ & $18,44 \pm 0,37 \mathrm{Cb}$ & $19,48 \pm 0,37 \mathrm{Aab}$ & $19,06 \pm 0,37 \mathrm{Bb}$ & $19,97 \pm 0,37 \mathrm{Aa}$ \\
\hline
\end{tabular}


Rev. bras. zootec.

Tabela 4 - Médias das características quantitativas da carcaça de animais por raça e por categoria ${ }^{1}$

Table 4 - Means of the quantitative carcass traits of animals by breed and category

Item

\begin{tabular}{ccll}
\multicolumn{3}{c}{$\begin{array}{c}\text { Raça } \\
\text { Breed }\end{array}$} \\
Gir & Guzerá & Nelore & Mocho Tabapuã \\
Gur & Guzera & Nellore & \\
\hline
\end{tabular}

\begin{tabular}{|c|c|c|c|c|}
\hline \multirow[b]{3}{*}{$\operatorname{COMPCAR}(C L), \mathrm{m}$} & \multirow{2}{*}{\multicolumn{4}{|c|}{-------------------------------------Valor absoluto------------------------------------ }} \\
\hline & & & & \\
\hline & $1,38 \pm 0,01 \mathrm{a}$ & $1,39 \pm 0,01 \mathrm{a}$ & $1,39 \pm 0,01 \mathrm{a}$ & $1,38 \pm 0,01 \mathrm{a}$ \\
\hline $\operatorname{ESPGOR}(B F T), \mathrm{mm}$ & $3,11 \pm 0,30 \mathrm{a}$ & $3,44 \pm 0,30 \mathrm{a}$ & $2,77 \pm 0,30 \mathrm{a}$ & $2,85 \pm 0,30 \mathrm{a}$ \\
\hline $\operatorname{AOL}(L E A), \mathrm{cm}^{2}$ & $55,35 \pm 3,07 \mathrm{a}$ & $54,59 \pm 3,07 \mathrm{a}$ & $58,56 \pm 3,07 \mathrm{a}$ & $54,02 \pm 3,07 \mathrm{a}$ \\
\hline $\begin{array}{l}\operatorname{COMPCAR}(C L), \mathrm{m} \\
\mathrm{ESPGOR}(B F T), \mathrm{mm} \\
\operatorname{AOL}(L E A), \mathrm{cm}^{2} \\
\end{array}$ & $\begin{array}{c}0,35 \pm 0,003 \mathrm{a} \\
0,80 \pm 0,07 \mathrm{a} \\
14,03 \pm 0,71 \mathrm{a} \\
\end{array}$ & $\begin{array}{c}-(\% \mathrm{PCVZ})(\% \\
0,35 \pm 0,003 \mathrm{a} \\
0,84 \pm 0,07 \mathrm{a} \\
13,58 \pm 0,71 \mathrm{a} \\
\end{array}$ & $\begin{array}{c}0,34 \pm 0,003 \mathrm{a} \\
0,68 \pm 0,07 \mathrm{a} \\
14,33 \pm 0,71 \mathrm{a}\end{array}$ & $\begin{array}{c}0,35 \pm 0,003 \mathrm{a} \\
0,71 \pm 0,07 \mathrm{a} \\
13,55 \pm 0,71 \mathrm{a}\end{array}$ \\
\hline \multirow[t]{3}{*}{ Item } & \multicolumn{4}{|c|}{ Categoria } \\
\hline & $405 \mathrm{~kg} P V(L W)$ & 450 & $(L W)$ & $500 \mathrm{~kg} P V(L W)$ \\
\hline & & $\begin{array}{r}-\mathrm{Va} \\
\mathrm{Al}\end{array}$ & 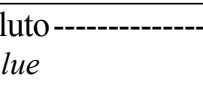 & ------------- \\
\hline $\operatorname{COMPCAR}(C L), \mathrm{m}$ & $1,35 \pm 0,01 \mathrm{c}$ & & $1 \mathrm{~b}$ & $1,42 \pm 0,01 \mathrm{a}$ \\
\hline $\operatorname{ESPGOR}(B F T), \mathrm{mm}$ & $2,17 \pm 0,26 b$ & & $6 b$ & $4,00 \pm 0,26 \mathrm{a}$ \\
\hline $\operatorname{AOL}(L E A), \mathrm{cm}^{2}$ & $47,53 \pm 2,66 b$ & & $56 a$ & $61,41 \pm 2,66 \mathrm{a}$ \\
\hline $\begin{array}{l}\operatorname{COMPCAR}(C L), \mathrm{m} \\
\mathrm{ESPGOR}(B F T), \mathrm{mm} \\
\operatorname{AOL}(L E A), \mathrm{cm}^{2}\end{array}$ & $\begin{array}{c}0,37 \pm 0,002 \mathrm{a} \\
0,61 \pm 0,06 \mathrm{~b} \\
13,12 \pm 0,62 \mathrm{a} \\
\end{array}$ & & $\begin{array}{l}6 E B W)- \\
2 \mathrm{~b} \\
6 \mathrm{ab} \\
62 \mathrm{a}\end{array}$ & $\begin{array}{c}0,32 \pm 0,002 \mathrm{c} \\
0,91 \pm 0,06 \mathrm{a} \\
13,87 \pm 0,62 \mathrm{a} \\
\end{array}$ \\
\hline
\end{tabular}

${ }^{1}$ Médias, na linha, seguidas por letras diferentes são diferentes $(\mathrm{P}<0,05)$ pelo teste Tukey.

${ }^{1}$ Means, within a row, followed by different letters are different $(P<.05)$ by Tukey test.

${ }^{2}$ COMPCAR = comprimento de carcaça; ESPGOR = espessura de gordura subcutânea; $\mathrm{AOL}$ = área de olho de lombo.

${ }^{2} \mathrm{CL}=$ carcass length; $B F T=$ back fat thickness; $L E A=$ loin eye area.

gordura entre 3 e $5 \mathrm{~mm}$ garante boa proteção às carcaças resfriadas. Dessa forma, os valores encontrados para animais abatidos aos 450 e $500 \mathrm{~kg}$ PV, no presente estudo, podem ser considerados adequados.

$\mathrm{O}$ valor de AOL do Nelore, em \% PCVZ, foi bastante próximo aos valores de 14,67 e 13,13 encontrados por GAZZETTA et al. (1995) e JORGE et al. (1997a), respectivamente, e inferior aos encontrados por GALVÃO et al. (1991), PERON et al. (1995) e MOLLETTA e RESTLE (1996).

Os animais abatidos aos $500 \mathrm{~kg}$ PV apresentaram maior $(\mathrm{P}<0,05)$ COMPCAR e ESPGOR e os das categorias 450 e $500 \mathrm{~kg} \mathrm{PV}$, maior $(\mathrm{P}<0,05)$ AOL, expressos em valores absolutos, que as demais categorias. Quando se ajustaram os dados em \% PCVZ, verificou-se que animais abatidos aos $500 \mathrm{~kg} P V$ apresentaram menor $(\mathrm{P}<0,05)$ COMPCAR que os de $450 \mathrm{~kg}$ e estes, menor $(\mathrm{P}<0,05)$ que animais abatidos aos $405 \mathrm{~kg}$ PV. Isso indica que animais aos $500 \mathrm{~kg}$ PV apresentaram carcaças mais compactas, em conseqüência do maior desenvolvimento dos seus tecidos moles, especialmente do adiposo e, em menor escala, do tecido muscular, na fase em que já teria ocorrido desaceleração do crescimento ósseo (BERG e BUTTERFIELD, 1976). Quanto à AOL, em \% PCVZ, não se verificou diferença entre categorias. Isto indica a ocorrência de desaceleração do desenvolvimento do tecido muscular em relação ao do tecido adiposo nos animais aos $500 \mathrm{~kg}$ PV, o que é confirmado pelo aumento dos valores de ESPGOR, em \% PCVZ, em animais mais pesados (500 kg PV). Estes resultados coincidem com os encontrados por GALVÃO et al. (1991), PERON et al. (1995) e JORGE et al. (1997a).

As proporções estimadas, segundo HANKINS e HOWE (1946), de músculos, tecido adiposo e ossos, e as suas relações na carcaça dos animais das quatro raças (Gir, Guzerá, Nelore e Mocho Tabapuã) e das três categorias (405 kg, $450 \mathrm{~kg}$ e $500 \mathrm{~kg}$ PV) são apresentadas na Tabela 5. Não houve diferença entre raças quanto às proporções de músculos e de tecido adiposo. Por outro lado, o Nelore apresentou maior $(\mathrm{P}<0,05)$ proporção de ossos que o Gir e Guzerá, não diferindo do Mocho Tabapuã, o qual, por sua vez não 
diferiu dos demais. A proporção de músculos no Nelore, do presente estudo, foi 10,$0 ; 6,4 ; 13,4 ;$ e $0,8 \%$ inferior à encontrada por GALVÃO et al. (1991), ESTRADA (1996), MOLETTA e RESTLE (1996) e JORGE et al. (1997a), respectivamente, e 3,0\% superior à encontrada por PERON et al. (1995).

Animais Guzerá apresentaram maior $(\mathrm{P}<0,05)$ relação tecido mole/osso (TM/O) e músculo/osso $(\mathrm{M} / \mathrm{O})$, enquanto o Nelore apresentou menor $(\mathrm{P}<0,05)$ $\mathrm{TM} / \mathrm{O}$ e $\mathrm{M} / \mathrm{O}$, o que é é explicado pela menor e maior proporção de ossos na carcaça, apresentada pelo Guzerá e pelo Nelore, respectivamente.

Não houve diferença entre as raças quanto às relações tecido adiposo/osso (TA/O) e tecido adiposo/ músculo (TA/M). Os resultados do presente estudo, para os animais Nelore, coincidem com os encontrados por ESTRADA (1996), que observou relação
TA/O e TA/M, de 1,90 e 0,48 , respectivamente, em animais abatidos aos 450 e $500 \mathrm{~kg}$ de peso vivo.

Não se observou diferença entre as categorias de abate quanto à proporção de músculos e de tecido adiposo, embora tenha se observado tendência de maior proporção de tecido adiposo e ocorrido menor proporção $(\mathrm{P}<0,05)$ de ossos em animais abatidos aos $500 \mathrm{~kg} \mathrm{PV}$.

Animais abatidos aos $500 \mathrm{~kg}$ PV apresentaram maior $(\mathrm{P}<0,05)$ relação $\mathrm{TM} / \mathrm{O}, \mathrm{M} / \mathrm{O}$ e TA/O que animais aos $405 \mathrm{~kg}$ PV. Estas diferenças refletem, basicamente, as mudanças na proporção de ossos na carcaça, que reduziu acentuadamente com o aumento do peso vivo que a proporção de músculos. Estes resultados são sustentados por BERG e BUTTERFIELD (1976) e MARPLE (1983) e concordam com os encontrados por PERON et al. (1995), ESTRADA (1996).

Tabela 5 - Média da composição física da carcaça de animais, por raça e por categoria Table 5 - Mean of the physical composition of the carcass of animals, by breed and category

\begin{tabular}{|c|c|c|c|c|}
\hline \multirow[t]{3}{*}{ Tecido $^{2}$} & \multicolumn{4}{|c|}{ Raça (Breed) } \\
\hline & $\operatorname{Gir}(G y r)$ & Guzerá(Guzera) & Nelore(Nellore) & Mocho Tabapuã \\
\hline & \multicolumn{4}{|c|}{ Uazcia } \\
\hline Muscular (Muscles) & $55,41 \pm 1,60 \mathrm{a}$ & $55,40 \pm 1,60 \mathrm{a}$ & $54,41 \pm 1,60 \mathrm{a}$ & $56,40 \pm 1,62 \mathrm{a}$ \\
\hline Adiposo (Adipose) & $29,26 \pm 1,63 \mathrm{a}$ & $29,75 \pm 1,63 \mathrm{a}$ & $28,70 \pm 1,63 \mathrm{a}$ & $28,02 \pm 1,64 \mathrm{a}$ \\
\hline \multirow[t]{3}{*}{ Ósseo (Bone) } & $15,33 \pm 0,44 b$ & $14,85 \pm 0,44 b$ & $16,89 \pm 0,44 \mathrm{a}$ & $15,59 \pm 0,44 \mathrm{ab}$ \\
\hline & \multirow{2}{*}{\multicolumn{4}{|c|}{$\begin{array}{l}\text { Relações entre os tecidos } \\
\text { Relations among tissues }\end{array}$}} \\
\hline & & & & \\
\hline $\mathrm{TM} / \mathrm{O}(S T / B)$ & $5,60 \pm 0,19 a b$ & $5,85 \pm 0,19 \mathrm{a}$ & $4,97 \pm 0,19 b$ & $5,49 \pm 0,19 a b$ \\
\hline $\mathrm{M} / \mathrm{O}(M / B)$ & $3,64 \pm 0,15 \mathrm{ab}$ & $3,80 \pm 0,15 \mathrm{a}$ & $3,25 \pm 0,15 b$ & $3,66 \pm 0,15 a b$ \\
\hline $\mathrm{TA} / \mathrm{O}(A T / B)$ & $1,96 \pm 0,13 \mathrm{a}$ & $2,06 \pm 0,13 \mathrm{a}$ & $1,72 \pm 0,13 \mathrm{a}$ & $1,82 \pm 0,13 \mathrm{a}$ \\
\hline $\mathrm{TA} / \mathrm{M}(A T / M)$ & $0,54 \pm 0,05 \mathrm{a}$ & $0,54 \pm 0,05 \mathrm{a}$ & $0,54 \pm 0,05 \mathrm{a}$ & $0,50 \pm 0,05 \mathrm{a}$ \\
\hline Tecido $^{2}$ & \multicolumn{4}{|c|}{ Categoria } \\
\hline \multirow[t]{2}{*}{ Tissue } & \multicolumn{4}{|c|}{ Category } \\
\hline & $405 \mathrm{~kg} \mathrm{PV}(L W)$ & $450 \mathrm{~kg}$ PV & & $500 \mathrm{~kg} \mathrm{PV}(L W)$ \\
\hline & & - & ---- & \\
\hline Muscular (Muscles) & $56,13 \pm 1,39 a$ & $54,53 \pm 1,4$ & & $55,55 \pm 1,39 a$ \\
\hline Adiposo (Adipose) & $27,27 \pm 1,41 \mathrm{a}$ & $29,22 \pm 1$, & & $30,31 \pm 1,41 \mathrm{a}$ \\
\hline \multirow[t]{3}{*}{ Ósseo (Bone) } & $16,60 \pm 0,38 \mathrm{a}$ & $16,23 \pm 0,3$ & & $14,14 \pm 0,38 b$ \\
\hline & \multirow{2}{*}{\multicolumn{4}{|c|}{$\begin{array}{l}\text { Relações entre os tecidos } \\
\quad \text { Relations among tissues }\end{array}$}} \\
\hline & & & & \\
\hline $\mathrm{TM} / \mathrm{O}(S T / B)$ & $5,07 \pm 0,16 b$ & $5,23 \pm 0,1$ & & $6,12 \pm 0,16 a$ \\
\hline $\mathrm{M} / \mathrm{O}(M / B)$ & $3,42 \pm 0,13 b$ & $3,38 \pm 0,1$ & & $3,96 \pm 0,13 \mathrm{a}$ \\
\hline $\mathrm{TA} / \mathrm{O}(A T / B)$ & $1,65 \pm 0,11 b$ & $1,85 \pm 0,1$ & & $2,16 \pm 0,11 \mathrm{a}$ \\
\hline $\mathrm{TA} / \mathrm{M}(A T / M)$ & $0,49 \pm 0,04 \mathrm{a}$ & $0,55 \pm 0,0$ & & $0,56 \pm 0,04 \mathrm{a}$ \\
\hline \multicolumn{5}{|c|}{ Médias, na linha, seguidas por letras diferentes são diferentes $(P<0,05)$ pelo teste Tukey. } \\
\hline \multirow{2}{*}{\multicolumn{5}{|c|}{$\begin{array}{l}1 \mathrm{Means,} \text { within a row, followed by different letters are different }(P<.05) \text { by } \text { Tukey test. } \\
\mathrm{M}=\text { músculos; TA = tecido adiposo; } \mathrm{O}=\text { ossos; e relaçôes: } \mathrm{TM} / \mathrm{O}=\text { tecido mole } / \text { ssos; } \mathrm{M} / \mathrm{O}=\text { tecido muscular/ossos; TA } / \mathrm{O}=\text { tecido adiposo/ } \\
2 \text { Tecido mole = Tecido adiposo/muscular. }\end{array}$}} \\
\hline & & & & \\
\hline \multicolumn{5}{|c|}{$\begin{array}{l}{ }^{1} M=\text { muscles; } A T=\text { adipose tissue; } B=\text { bone; and relations: } S T / B=\text { soft tissue } 2 / \text { bone; } M / B=\text { muscles } / \text { bone; } A T / B=\text { adipose tissueo } / \text { bone and } A T / M=\text { adipose } \\
\text { tissue } / \text { muscles. }\end{array}$} \\
\hline
\end{tabular}




\section{Conclusões}

Não há diferença entre raças e entre pesos de abate (405 a $500 \mathrm{~kg} \mathrm{PV}$ ), quanto aos rendimentos de carcaça em relação ao peso corporal vazio, quanto aos rendimentos dos cortes dianteiro, paleta completa, traseiro total e coxão e quanto às proporções de músculos e de tecido adiposo.

As raças não diferem entre si, quanto ao comprimento de carcaça, à espessura de gordura subcutânea, à área de olho de lombo e à proporção de músculos e de tecido adiposo da carcaça.

Os animais abatidos com pesos mais elevados apresentam menores proporções de ossos e menores comprimentos de carcaça por $100 \mathrm{~kg}$ de peso corporal vazio, indicando carcaças mais compactas.

\section{Referências Bibliográficas}

BERG. R. T., BUTTERFIELD, R. M. 1976. New concepts of cattle growth. New York: Sydney University, 240p.

ESTRADA, L.H.C. Composição corporal e exigências de proteína, energia e macroelementos minerais ( $\mathrm{Ca}, \mathrm{P}, \mathrm{Mg}, \mathrm{Na}$ e $K)$, características da carcaça e desempenho do Nelore e mestiços em confinamento. Viçosa, MG, 129p. Tese (Doutorado em Zootecnia) - Universidade Federal de Viçosa, 1996.

GAlVÃo, J. G., FONTES, C. A. A., PIRES, C. C. et al. 1991. Ganho de peso, consumo e conversão alimentar em bovinos não-castrados, de três grupos raciais, abatidos em diferentes estágios de maturidade (estudo I). R. Soc. Bras. Zootec., 20(5):494-501.

GAZZETTA, M. C. R. R., ITURRINO, R. P. S., CAMPOS, B. E. S. et al. 1995. Avaliação corporal de búfalos (Bubalus bubalis) e bovinos Nelore (Bos indicus), terminados em confinamento. Bol. Ind. Anim., 52(1):77-86.

GONÇALVES, L.C. Digestibilidade, composição corporal, exigências nutricionais e características das carcaças de zebuínos, taurinos e bubalinos. Viçosa, MG: UFV, 1988. 238 p. Tese (Doutorado em Zootecnia) - Universidade Federal de Viçosa, 1988.

HANKINS, O.G., HOWE, P.E. 1946. Estimation of the composition of beef carcasses and cuts. Washington, D. C., (Tech. Bulletin - USDA, 926).
HARVEY, W. R.1987. Mixed model least squares and maximum likelihood computer program (LSMLMW) Versão PC - 1.

JORGE, A.M., FONTES, C.A.A., SOARES, J.E. et al. 1997a. Características quantitativas da carcaça de bovinos e bubalinos, abatidos em diferentes estágios de maturidade. $R$. Bras. Zootec., 26(5):1039-1047.

JORGE, A.M., FONTES, C.A.A., FREITAS, J.A. et al. 1997b. Rendimentos de carcaça e de seus cortes básicos de bovinos e bubalinos, abatidos em diferentes estágios de maturidade. R. Bras. Zootec., 26(5):1048-1054.

MARPLE, D.N. Principles of growth and development. In: GROWTH MANAGEMENT CONFERENCE, 1983, Indiana. Proceedings... Indiana: IMC, p. 1-6, 1983.

MOLETTA, J.L., RESTLE, J. 1996. Características de carcaça de novilhos de diferentes grupos genéticos terminados em confinamento. R. Soc. Bras. Zootec., 25(5):876-888.

NATIONAL RESEARCH COUNCIL - NRC. 1984. Nutrient requeriments of beef cattle. 6. ed. Washington, D. C., 90p.

PAULINO, M. F. Composição corporal e exigências de energia, proteína e macroelementos minerais ( $\mathrm{Ca}, \mathrm{P}, \mathrm{Mg}$, Na e K) de bovinos não-castrados de quatro raças zebuínas em confinamento. Viçosa, MG: UFV, 1996. 80p. Tese (Doutorado em Zootecnia) - Universidade Federal de Viçosa, 1996.

PERON, A. J., FONTES, C. A. A., LANA, R. P. et al. 1993. Rendimento da carcaça e de seus cortes básicos e área corporal de bovinos de cinco grupos genéticos, submetidos a alimentação restrita e "ad libitum". R. Soc. Bras. Zootec., 22(2):238-247.

PERON, A. J., FONTES, C. A. A., LANA, R. P. et al. 1995. Medidas quantitativas e proporções de músculos, tecido adiposo e ossos da carcaça de novilhos de cinco grupos genéticos, submetidos à alimentação restrita e "ad libitum". R. Soc. Bras. Zootec., 24(1):126-137.

Recebido em: $23 / 04 / 98$

Aceito em: 24/09/98 